\title{
Pensamiento y acción americanista en los liberales chilenos: la propuesta de Benjamín Vicuña Mackenna, 1862-1868
}

\author{
Americanist thougth and action in chilean liberals: \\ the proposal of Benajamin Vicuña Mackenna, 1862-1868
}

\author{
LORENA UBILLA ESPINOZA \\ Universidad Diego Portales, Facultad de Psicología. Chile. \\ Correo electrónico: lorena.ubilla@mail.udp.cl
}

En 1862 diversos intelectuales liberales fundaron la Sociedad Unión Americana de Santiago con el fin de contrarrestar los intentos de restauración colonial en el continente. A partir del análisis de los documentos y de las actas publicadas al alero de esta entidad, este ensayo discutirá qué entendieron por americanismo los liberales chilenos a mediados del siglo XIX y, específicamente, cuál fue la propuesta que Benjamín Vicuńa Mackenna expresó sobre el rol que debía cumplir Estados Unidos en este esfuerzo confederativo. A modo de hipótesis se plantea que las diferencias del político obedecieron tanto a su experiencia como agente confidencial en el país del norte, como a un interés mayor por legitimar el proyecto liberal en el marco de las disputas con los conservadores en la segunda mitad del siglo XIX.

Palabras claves: americanismo, liberalismo, Sociedad Unión Americana de Santiago, Benjamín Vicuña Mackenna, Estados Unidos.

The European eagerness for colonial restoration led various intellectuals to found in 1862 the "American Union of Santiago" to defend independence and promote the union of their republics. From the analysis of documents and acts published by this entity, in this article we review what was understood by americanism in the mid-19th century and what were the common and discordant points expressed among the Chilean liberals, specifically the proposals of Benjamin Vicuña Mackenna about the role that the United States should play in the unionist effort. This article argues that the Vicuña Mackenna's differences were due to his own experience as a confidential agent in the United States and a greater interest in legitimizing the liberal project in the context of disputes with the conservatives in the second half of the 19th century.

Key words: americanism, liberalism, American Union Society of Santiago, Benjamin Vicuña Mackenna, United States of America. 


\section{Presentación}

La década de 1860 estuvo marcada por una serie de intentos colonialistas que buscaban desestabilizar el proceso independentista y de construcción del Estado en el continente. La anexión de República Dominicana por parte de España en 1861, la segunda intervención francesa en México en $1862^{1}$ y la ocupación de las Islas Chincha peruanas por la monarquía española en $1865,{ }^{2}$ impactaron en una generación de políticos e intelectuales liberales que discutieron y reformularon las bases del americanismo bolivariano. Entre ellos destacaron Miguel Luis Amunátegui, Pedro León Gallo, Manuel Antonio y Guillermo Matta, José Victorino Lastarria, Domingo Santa María y Benjamín Vicuña Mackenna, quienes fundaron en 1862 la Sociedad Unión Americana de Santiago. Con el objetivo explícito de defender la independencia y promover la unión de las repúblicas en el continente, recopilaron documentos sobre el pensamiento y acción de los precursores independentistas, además de publicar las actas de las reuniones y escritos de su propia autoría. Las dos obras, Colección de ensayos y documentos relativos a la Unión y Confederación de los pueblos hispanoamericanos y Bases de la Sociedad de la Unión Americana, se publicaron en 1867 y resultan de interés para comprender los cambios y continuidades del americanismo que abrazaron los liberales a mediados del siglo XIX en relación con aquél propuesto por los libertadores a comienzos de la centuria.

En este marco destacó la figura del multifacético Benjamín Vicuña Mackenna, específicamente porque $-\mathrm{y}$ a diferencia de otros intelectuales liberales que participaron en la Sociedad- no se limitó a cuestionar el afán colonialista de las potencias europeas, sino que expresó un americanismo hispanoamericano que cuestionaba las bases de la Doctrina Monroe y las pretensiones anexionistas y expansionistas de los Estados Unidos de Norteamérica. En 1865, el presidente José Joaquín Pérez lo envió como agente confidencial al país del norte con el objeto de comprar armamentos y buques, además de conseguir préstamos para financiar la guerra que Chile y Perú libraban en el Pacífico con los hispanos. En Nueva York adquirió cuatro navíos, uno de los cuales zarpó a Chile, razón que el gobierno norteamericano esgrimió para detenerlo acusado de violar las leyes de neutralidad y de dirigir una expedición militar contra los dominios españoles de Cuba y Puerto Rico. Tras tres meses de juicio se le declaró culpable, aunque conoció la sentencia a su regreso pues poco después de este incidente el presidente Pérez lo envió de retorno a Chile (Donoso

\footnotetext{
${ }^{1}$ En diciembre de 1861 desembarcaron en México tropas combinadas de Francia, España e Inglaterra tras la suspensión del pago de la deuda pública decretada por el gobierno de Benito Juárez. Frente a ello, en mayo de 1862, un nuevo destacamento francés, apoyado por los conservadores mexicanos, proclamó el establecimiento del Imperio con Maximiliano de Habsburgo al mando de la corona.

${ }^{2}$ El 14 de abril de 1864 la Armada Española ocupó el territorio peruano de Islas Chincha, ricas en guano y fuente del 30\% del erario nacional. En solidaridad a esta acción, Chile, Ecuador y Bolivia declararon la guerra a España. Por su parte, Argentina, Uruguay y Brasil se negaron a participar, declararon su neutralidad y se embarcaron en la guerra contra Paraguay conocida como Triple Alianza. En el caso chileno, el conflicto se extendió por dos años e incluyó el bombardeo de Valparaíso por parte de la escuadra espańola (ver Lacoste 1997).
} 
1925; Orrego 1932; Orrego 1939; Guerrero 1986). Ante las explicaciones solicitadas por el Parlamento chileno, escribió Diez meses de misión a los Estados Unidos de Norte América, texto fundamental para comprender los alcances de sus propuestas sobre la unión americana. En las páginas que siguen se problematizará la manera en que este intelectual liberal comprendió el americanismo entre 1862, año de la fundación de la Sociedad, y 1868, momento del primer alzamiento independentista en Cuba. Aunque las disputas por la construcción de lo americano varían atendiendo al contexto, pertenencia social y marcos nacionales, entenderemos el americanismo de mediados del siglo XIX como fruto de una reflexión y práctica histórica nacida de la lucha anti-colonial y fundamentada en los procesos de construcción nacional (López 2011, 2013). Al respecto, se plantea que la visión de Vicuña Mackenna sumó aspectos específicos a este sustrato común, particularmente la pregunta por la relación entre Hispanoamérica y Estados Unidos, lo cual respondió a su experiencia como agente confidencial y a un interés más amplio por legitimar el proyecto liberal de construcción estatal.

Tras una breve introducción sobre liberalismo y modernización, la exposición se estructura en dos apartados que toman como base el análisis documental. Primero, se presentan las ideas centrales de Colección de ensayos y documentos relativos a la Unión y Confederación de los pueblos hispanoamericanos, con el fin de exponer los puntos comunes que compartió este grupo de liberales sobre la acción y gesta americanista. Y segundo, a partir de la revisión de las columnas, artículos y ensayos escritos por Vicuña Mackenna en el periódico La Voz de la América $a^{3}$ en la recopilación titulada Miscelánea $a^{4}$ en Diez meses de misión en los Estados Unidos de Norte América, se releva la especificidad de su experiencia personal y de su propuesta sobre la unión continental.

\section{ELITE, LIBERALISMO Y MODERNIZACIÓN}

El nacimiento de las repúblicas americanas, el rol de los primeros hombres de Estado, las disputas políticas sobre el pasado reciente y la conciencia del carácter fundacional del relato histórico fueron las materias que ocuparon a la primera generación de intelectuales latinoamericanos (Romero 1976)5 ${ }^{5}$. En el caso de Vicuña Mackenna, por ejemplo, los libros

\footnotetext{
${ }^{3}$ En Nueva York, y junto al escritor veneciano Marcos Paolo, fundó el periódico La Voz de la América. Órgano politico de las Repúblicas Hispanoamericanas y de las Antillas Españolas, el 21 de diciembre de 1865. Sus columnas recibieron centenares de artículos, ensayos, correspondencias, proclamas y colaboraciones de escritores y políticos, entre ellos, el intelectual argentino Domingo Faustino Sarmiento y el presidente de la Sociedad Republicana de Cuba y Puerto Rico, Manuel Macías.

${ }^{4}$ Texto de carácter recopilatorio subtitulado Colección de artículos, discursos, biografías, impresiones de viaje, ensayos, estudios sociales, económicos, etc. 1849-1872, publicado en tres tomos los años 1872, 1873 y 1874.

${ }^{5}$ Para José Luis Romero, el vigor de la ideología nacionalista se manifestó en las obras de la primera generación de historiadores que se propusieron indagar en la formación de los Estados y su articulación con la nación. Entre ellos destaca a los mexicanos Lucas Alamán y José María Mora, al cubano José Antonio Saco, al colombiano José
} 
dedicados a José Miguel Carrera (1857) y Bernardo O’Higgins (1860), tuvieron como fin reconciliar a la clase dirigente en el marco de los conflictos por el poder que sostenían airadamente liberales y conservadores (Renique 2007; Vicuña 2009) ${ }^{6}$.

En términos generales, y considerando el recorte temporal propuesto, los liberales se identificaron con la apertura de la sociedad a la matriz europea, con las críticas al autoritarismo presidencial y con un fuerte proyecto de laicismo social y cultural. Aunque contrarios a los regímenes absolutistas y monárquicos, estos principios no impidieron que en la práctica fueran partícipes de la construcción de un Estado con importantes resabios coloniales (Stuven 2005). Dicha contradicción se explica porque, a diferencia de Europa, el liberalismo latinoamericano no fue la expresión ideológica del fortalecimiento y consolidación de la burguesía, sino que fue asumida por una fracción de la aristocracia que siguió ligada a las estructuras de dominación colonial, sobre todo a la propiedad de la tierra en el campo y a la explotación extensiva de la mano de obra.

La contradicción entre libertad e igualdad como conceptos universales y principios políticos y materiales excluyentes, explica que la tradicional división entre liberales y conservadores cobre sentido fundamentalmente en términos discursivos. Abocados en conjunto a la construcción y organización del Estado dentro de un ideario constitucionalistarepublicano, el liberalismo se configuró ante todo por su alto contenido racionalista, secularizador y negador de la tradición.

Para Adam Anderle (1988), dicha conjunción liberal-conservadora se explica, además, a la luz de la adopción latinoamericana del positivismo, cuyo principio de orden y progreso fue el sustento que les posibilitó superar sus diferencias y, más aún, conservar su hegemonía por más de un siglo. En tanto instrumento para la prosperidad económica (progreso) y para la legitimación del poder (orden), esta entrada desde arriba a la modernidad respondía a la consciencia de vivir en una época que consideraban nueva en relación con un pasado inmóvil y tradicional. Y, efectivamente, fue este sentimiento de superioridad el que los llevó a interpretar la historia y otras realidades vivenciales como incompletas e inmaduras.

A mediados de siglo, la atmósfera intelectual liberal se dividía en una corriente de carácter republicano con énfasis en el bien común, y otra de cuño liberal que apelaba a la promoción de los derechos individuales (Subercaseaux 1980). Pese a compartir un tronco afín, a medida que se discutía la ampliación de la democracia, una importante fracción fue cerrando filas con los conservadores en torno al orden republicano y al autoritarismo presidencial (Stuven 2000; Castillo 2003). Según Jocelyn-Holt (1998) esta corriente de

María Restrepo, al boliviano Mariano Paz Soldán, a los argentinos Bartolomé Mitre y Vicente Fidel López, y a los chilenos Diego Barros Arana y Benjamín Vicuña Mackenna.

${ }^{6}$ Pese a compartir un marco positivista, la propuesta escritural de Vicuña Mackenna destaca por desarrollarse al calor de los hechos mismos. Recopilando una serie de documentos y testimonios de los actores directos, bien se puede argumentar que desarrolló una embrionaria historia oral al instalarse como mediador entre la memoria de los testigos y la elaboración escrita (historiográfica) a partir de esos relatos del pasado. Al respecto, ver Gazmuri (2006) y Vicuña (2009). 
"liberalismo moderado" fue la que se impuso en la década de 1860 y en el quinquenio inmediatamente posterior. Sustentados en el carácter señorial, rural y jerárquico que les permitía asegurar la preeminencia oligárquica, pudieron congeniar cambio y orden y promover un marco de tolerancia y pluralismo en una sociedad todavía tradicional.

La propuesta liberal se materializó y consolidó asociada al proyecto modernizador, capitalista y periférico que vivió el país en el último cuarto del siglo XIX. Es decir, la inserción en los circuitos comerciales fue la forma que encontraron para resolver el conflicto entre sus resabios coloniales -que los igualaban a los conservadores- y el proceso de transición librecambista (Cavieres 2001). Tanto fue así que la mayoría de los países latinoamericanos miró a Europa en busca de mercados, esperando recibir de ella capitales para sus proyectos de desarrollo económico. Un breve ciclo de estas inversiones se produjo en la década de 1820, aunque el momento a gran escala comenzó en 1860 con la mayor parte del capital procedente de Gran Bretańa, Francia y Alemania (Freeman 2000). En este caso, y considerando la propuesta americanista, poco les importó a los liberales el historial de intervenciones militares pasadas y presentes en el continente por parte de las potencias metropolitanas.

Para Bernardo Subercaseaux (1980) la categoría de "elite ilustrada" permite comprender esta conjunción de intereses y su concentración en tanto bloque de poder, dado que las disputas en ámbitos como la libertad de prensa, de educación, o laicización de la sociedad, en ningún caso pusieron en riesgo su posición de clase social dominante. Con todo, tampoco es posible caracterizar de forma homogénea sus intereses y diferencias políticas, pues en las elites conviven posiciones que cumplen un rol de autoridad en coyunturas específicas y en ámbitos particulares de acción (Sagredo 1996). No atender a ello convertiría su estudio en una categoría abstracta que poco ayuda a situarla en el contexto social e intelectual de la época. En ese sentido, las diversas acepciones de americanismo que circularon hacia mediados del siglo XIX dan cuenta de estos matices sobre la construcción de un proyecto nacional, además de entregar luces respecto al rol que los liberales $y$, especialmente Vicuña Mackenna, asignaron a las repúblicas hispanoamericanas en el nuevo concierto internacional.

\section{I.}

El 25 de mayo de 1862 sesionó por primera vez la Sociedad Unión Americana de Santiago bajo los objetivos de:

$1^{\circ}$ sostener la Independencia Americana y promover la unión de los diversos Estados de la América. $2^{\circ}[\ldots]$ uniformar a este respecto las ideas de todos los americanos e interponer su fuerza moral para conseguir que los gobiernos obren en el mismo sentido. $3^{\circ}[\ldots]$ discutir y presentar al examen público las bases que pudieran servir a la unión de los países americanos (1867a: 69). 
La organización, pensada en un comienzo a modo de protesta por la anexión española de Santo Domingo y de la expedición francesa en México, continuó sus reuniones hasta 1867 , sin que existiera un lazo directo con el gobierno. En una clara crítica a las políticas expansionistas europeas, los firmantes ${ }^{7}$ dieron vida a la organización con el fin explícito de revitalizar los intentos de unión de comienzos de siglo.

Causa y gesta americana fueron las expresiones que utilizaron para referirse a este tipo de americanismo. Los documentos y escritos contenidos en Colección de ensayos y documentos relativos a la unión y confederación de los pueblos americanos apelaban a una comunidad de naciones hermanadas por un hito fundacional de colaboración regional. La idea, evidenciada en alegorías, simbolismos y propuestas, expresaba un anhelo común a defender: la soberanía nacional frente a la intervención extranjera y el respeto al derecho constitucional frente a la fuerza militar. Bajo ese argumento cuestionaron las proclamas emancipatorias nacidas en el viejo continente, dirigiendo sus arengas de forma transversal "a los gobernantes y sus pueblos", e instando a organizar entidades de defensa del honor continental mancillado ante las "nuevas injusticias" -desconocimiento de la soberanía nacional- y "nuevos atentados" ${ }^{8}$-expediciones militares- (Sociedad de Unión Americana 1867a: 12).

El análisis sobre la semántica del tiempo histórico permite conectar esta sensación de autoconciencia, de sentirse actores y partícipes de una época de profundos cambios y de ruptura con un orden tradicional (Koselleck 1993). El advenimiento de la modernidad (que para estos intelectuales representaba lo opuesto al período colonial) los llevó a considerar el pasado como un tiempo estático, mientras que el presente se configuró como el espacio de la acción que permitía construir y transformar el futuro de estas recientes naciones. Por ello, y conscientes de vivir en un momento colectivo emparentado con sucesos históricos fundacionales -la Independencia y la construcción del Estado-, la convocatoria a revitalizar la "Patria Grande" resonó fuertemente en esta generación de liberales.

Considerando las actas y acuerdos firmados se aprecian, a lo menos, dos premisas sobre la concepción americanista contenida en el documento. Primero, la idea de que el "Nuevo Mundo" no era una realidad geográfica-espacial, sino, ante todo, una unidad política y cultural. América era el lugar en el que se habían llevado a la práctica las promesas de democracia y libertad forjadas en la Ilustración europea, contrarrestando la realidad política del viejo continente que buscaba perpetuar sus monarquías y aspiraciones coloniales. Las Américas emergían, así, como un espacio físico y simbólico que daba vida y sentido concreto a los contenidos independentistas, y aunque las estructuras coloniales

\footnotetext{
${ }^{7}$ Encabezaron la asociación Gregorio de las Heras y Marcos Maturana, ambos veteranos de las guerras de la independencia. En su composición también participaron antiguos conservadores que se habían distanciado del gobierno de Manuel Montt, además de políticos del recientemente fundado Partido Radical (1863).

${ }^{8}$ En las actas de la Sociedad se consigna que organizaciones con fines similares y nombres casi idénticos se crearon en ciudades como La Serena, San Felipe, Valparaíso y Quillota, y en otros países sudamericanos, como Argentina, Perú y Bolivia.
} 
permanecieran intactas, en términos discursivos servía para demostrar cómo construir una sociedad bajo principios racionales y modernos (Pratt 1997).

En el prólogo que abre la Colección, Vicuña Mackenna apeló a esta visión sobre el continente y al rol que cumplían los liberales como generación heredera y continuadora de la gesta de los primeros libertadores:

La confederación de los pueblos por el amor y la fraternidad es la independencia (1810), es la unión americana (1862). Así se cumplirán en el porvenir los destinos de esta Patria común, el más magnífico de los cinco grandes continentes que la mano del Eterno vació en el molde de su omnipotencia y al que un piloto sublime llamó "el Nuevo Mundo" porque en sus portentos era como una segunda y maravillosa Creación (i 867a: 158. Destacado en el original).

En la misma línea, la circular escrita por Manuel Antonio Matta sobre la confederación argentina agregaba razones de por qué América era la tierra de los sueños realizables:

Estamos en América, estamos en el país [...] de las quimeras, en el país que el loco de Colón vino a descubrir a pesar de las mofas de los grandes y los sabios de Europa [...] La quimera de la Unión Americana no es más irrealizable que lo que fue la heroica y también condenada quimera de nuestra independencia (Sociedad de Unión Americana 1867a: 78-79).

En segundo lugar, subyace en el documento una visión unificada sobre el americanismo, sus principales precursores y qué países debían incluirse en esta proclama. Esta concepción se sustentaba en un pasado reciente de convocatorias a alianzas y congresos y, un poco más lejano en el tiempo, en el actuar independentista. Al hablar de América se apelaba al continente en su conjunto, sin diferenciar colonización, idioma o historias, pues lo que hermanaba a sus países eran las luchas anticoloniales, el levantamiento mancomunado de sus pueblos y la defensa activa de su soberanía. Para José Victorino Lastarria, el accionar de los liberales reunidos en la Sociedad, evidenciaba esta confianza en que los hombres y los pueblos del continente cumplirían -nuevamente- con su destino aleccionador:

Somos pueblos nuevos y casi huérfanos en el mundo. Allá en Europa, en ese centro de civilización y poder, no se quiere creer en nuestra virtud, en nuestra dignidad, en nuestra gloria... y se pretende ver en América solamente pasiones antisociales, instintos salvajes, en lugar de principios de razón y justicia [...] La verdad en política nos llevará al goce de la libertad; en moral nos dará aquel principio de justicia que hace grandes a los pueblos y que les da un poder fecundo. Sólo así llenará la América su misión celeste, y devolverá al Viejo Mundo, purificada, esa civilización emponzonáa que hoy se irradia de aquella 
gran hoguera, en que se consumen tantos siglos (Sociedad de Unión Americana 1867a: 93-94).

Este americanismo sesentero, a diferencia de aquel nacido pre y post independencia, se había nutrido de una experiencia concreta de formación del Estado-nación, de ahí que las nuevas intervenciones militares se comprendieran como un atentado a la identidad hispanoamericana (López 2011). En términos específicos, se sustentaba en la convicción de resguardar la soberanía territorial e institucional, y en términos amplios, apelaba a esa “comunidad imaginada" forjada en el relato histórico anticolonial, el cual trascendía a los gobiernos en el poder pues simbolizaba la entrada al progreso, a la modernidad y a las "leyes" de la Historia. De hecho, fueron estos argumentos los que dieron vida a la publicación de Bases de la unión americana, documento de carácter consultivo que dictaminaba, entre otras disposiciones, la creación de un parlamento confederado cuyo fin era representar a todas las repúblicas en el concierto americano e internacional ${ }^{9}$.

Los textos reunidos en Colección... contienen dos partes prologadas por Vicuña Mackenna. En la primera se presentan los proyectos de unión continental, partiendo por los "Protocolos del Congreso de Panamá", convocado por Simón Bolívar en 1826, seguido de los "Protocolos del Congreso de Lima", aprobados en 1848, y finalizando con el "Tratado que fija las bases de unión para las repúblicas americanas". La segunda parte recoge un conjunto de variados escritos de americanistas chilenos e hispanoamericanos escritos a lo largo del siglo XIX, en los que se discuten las premisas de la unidad y las propuestas de medidas institucionales para concretar los intentos confederativos.

En esta selección de escritos la visión bolivariana fue la más aplaudida y recurrentemente citada como expresión de la unidad americana. Probablemente ello se condice con las historias personales de los liberales chilenos, quienes, perseguidos en los gobiernos conservadores, debieron emigrar a distintos países sudamericanos, entablando relaciones con otros intelectuales y exiliados políticos del continente. En ese sentido, estas experiencias les sirvieron para evidenciar que las disputas entre liberales y conservadores no contribuían al ideal unionista y, menos aún, a la consolidación de los principios republicanos (Renique 2007). De hecho, para muchos el destierro se transformó en una suerte de viaje de formación que cumplió una función de validación intellectual y que operó como un espacio intersticial en su legitimación pública y privada (Bintrup 1993; Sanhueza 2010). En el caso de Vicuña Mackenna, los exilios que sufrió en 1852 y 1858, le permitieron recopilar fuentes y colecciones bibliográficas con las que esperaba construir un archivo común hispanoamericano tras la dispersión documental que implicó la separación con España (Vicuña 2009: 63-66).

\footnotetext{
${ }^{9}$ El texto se compuso de cinco capítulos referidos a los estatutos de la sociedad, a la conformación y miembros del congreso de plenipotenciarios y a la creación de un ejército y armada común. Entre las atribuciones del parlamento destacaban: a) examinar y decidir sobre los problemas de los países integrantes de la sociedad, especialmente sus disputas limítrofes y de jurisdicción, b) determinar el presupuesto, contingente militar y dinero que debía aportar cada Estado anualmente, y c) dirigir las relaciones diplomáticas con otros países fuera del continente y vigilar que no se celebraran tratados con exenciones o privilegios especiales.
} 
Como se dijo más arriba, en ambos documentos -Colección y Bases...- no se cuestionó la incorporación de Estados Unidos a las alianzas unionistas pues se entendía que el país del norte compartía una historia de lucha común, dando vida a una constitución política basada en el principio de libertad individual. Tal como se indicaba en la declaración de principios: "En su lucha de justicia y humanidad, los Estados Unidos del Norte pueden contar con las simpatías de nuestras repúblicas democráticas” (Sociedad de Unión Americana 1867b: 93-94). Es decir, ambas Américas, del sur y del norte, configuraban política y discursivamente una historia que contenía en sí misma el triunfo republicanoconstitucionalista y el porvenir del Nuevo Mundo.

Sin embargo, esta visión sobre Estados Unidos era declarativa y, en cierta medida, hasta pragmática. Para una fracción de los participantes, el vínculo continental se sostenía en una oposición común a la monarquía, aunque lo americano resultaba fundamentalmente una propiedad de las antiguas colonias espańolas. Para otro grupo, entre los que se encontraba Félix Vicuña, Estados Unidos era un referente al que había que considerar en tanto representaba una modernidad distinta a la europea. Y un último grupo, probablemente al que adscribía Vicuña Mackenna, la alianza con el vecino del norte constituía una estrategia para ganar aliados, pero no un referente de identidad americana (López 2011). De hecho, en un artículo publicado con anterioridad a 1860 y previo, por tanto, a su misión como agente confidencial, el político liberal expresó que la acción americanista sólo debía incluir a los países de Hispanoamérica, dado que el poder y engrandecimiento de los Estados Unidos se sustentaba en una política exterior expansionista: "Nosotros [refiriéndose a los gobiernos sudamericanos] tenemos al menos la mitad de la culpa en esta crisis de conquista y de vandalaje que va haciéndose un mal crónico en nuestras repúblicas; nuestra DESUNIón es el principal elemento en el que se apoya el filibusterismo" (Vicuña Mackenna [1856] 1872b: 198. Destacado en el original). Así, el llamado que hacía a gobernantes y pueblos era actuar mancomunadamente en pos de frenar dichos avances:

Hoy es Nicaragua, mańana puede ser la Guaira en Venezuela, Guayaquil en el Ecuador, Chiloé en nuestras costas... Aprestémonos pues todos a nombre de la salvación común y salvémonos los unos por los otros, y que esta alianza que reclama la dignidad de nuestra raza sea pronta y cordial. Este solo gran medio tenemos a la mano para salvarnos y hacernos no solo invencibles sino inatacables [...] Que nuestra mutilada familia que cuenta tantas denominaciones de mutua hostilidad, "peruanos", "chilenos", "colombianos", "argentinos" sea solo un nombre delante del nombre americano [...] Que nuestras divididas repúblicas sean una sola América delante de las repúblicas unidas del Norte ([1856] 1872: 198. Destacado en el original).

Esta postura de Vicuña Mackenna permite poner en contexto una retórica pública más amplia que comenzó a circular a mediados de 1850 y que daba cuenta de una inquietud respecto al creciente poderío y expansionismo estadounidense, expresada entre otros, por 
Justo Arteaga Alemparte y Francisco Bilbao. Aunque dichos discursos nunca pusieron en duda la admiración por su sistema democrático, sí fueron expresivos de un resquemor hacia el país del norte que se volvió más fuerte y sistemático hacia fines de 1860, a partir del contaste entre una cultura anglosajona y otra latina (Collier 2005: 243-244) ${ }^{10}$.

Un término como América, que a primera vista puede parecer neutral, contiene determinados modos de ver la realidad que se condicen con un momento histórico particular y que, en tanto imaginario, denotan un lugar enunciativo a disputar (Rojo 2001). En ese marco, las varias ideas de América contenidas en ambos documentos son expresivas tanto de la fortaleza de una identidad independentista como de la coyuntura específica derivada de las intervenciones europeas. E ilustran, por tanto, la autoría y postura individual, así como el contexto particular en el que se debatían las relaciones continentales y el lugar que debía ocupar en ellas el país del norte.

Los avances en la laicización y secularización de la sociedad, sumado a las reformas constitucionales, les permitieron a los liberales de la década de 1860 un mayor posicionamiento público y político, espacio que utilizaron para articular una narrativa colectiva que exigía su mayor participación en el entramado institucional del Estado. Sintiéndose los legítimos continuadores del proceso independentista, promovieron cambios que buscaban romper con las prácticas culturales implantadas por los conservadores, a quienes consideraban parte del pasado colonial. Por ello no sorprende que las propuestas de unión, y que la concepción sobre qué y quiénes detentaban la identidad americana, se convirtieran en una abierta disputa. En última instancia, se trataba de legitimar un relato histórico que los volvía herederos privilegiados de una gesta heroica que el imaginario estatal debía reconocer y consolidar.

\section{II.}

El 14 de abril de 1864 se iniciaron las acciones bélicas en el litoral peruano tras la ocupación de las Islas Chincha por parte de la Armada espańola. La prensa de Santiago y Valparaíso informó ampliamente sobre el desarrollo de los acontecimientos argumentando de que se trataba de una amenaza a la independencia hispanoamericana y al republicanismo de sus naciones (López 2013; Lacoste 1997).

A diferencia de las intervenciones en Santo Domingo y México, en esta ocasión el apoyo oficial trascendió lo meramente declarativo ${ }^{11}$. Con el fin de generar alianzas ofensivas

\footnotetext{
${ }^{10}$ Mónica Quijada (1998) plantea que la interpretación sobre la génesis y difusión del nombre de América Latina -atribuida al francés Michel Chevalier tras su libro de viajes publicado en 1836- ha sido asumida como una interpretación oficial pese a las refutaciones históricas que ha recibido. En su artículo examina las versiones previas que la ponen en duda y propone una interpretación atenta a las connotaciones simbólicas del nombre que facilitaron la difusión y adopción mayoritaria de esta denominación en el contexto del proyecto expansionista francés liderado por Napoleón III.

${ }^{11}$ Oficialmente Perú recibió el apoyo de sus vecinos tras el Congreso Americano celebrado en Lima entre 1864 y 1865. Chile ratificó el acuerdo el 5 de diciembre de 1865; Ecuador, el 30 de enero de 1866, y Bolivia, el 15 de febrero de 1866. Pese al discurso unionista proclamado en las notas diplomáticas previas, la reunión evidenció
} 
y defensivas con otros países del continente, el gobierno chileno envió como embajador a José Victorino Lastarria a Buenos Aires, Montevideo y Río de Janeiro ${ }^{12}$; José Nicolás Hurtado se dirigió a Ecuador; Manuel Antonio Matta a Colombia y Venezuela, y Benjamín Vicuńa Mackenna fue designado como agente confidencial en Estados Unidos ${ }^{13}$. En este último caso, sus funciones incluían "promover en la opinión de aquella República simpatías calurosas y abiertas por nuestra causa [...] que empujen al gobierno de los Estados Unidos a obrar activamente en nuestro favor" (Vicuña Mackenna 1867, vol. 1: 13). De esta forma, se activaba un "americanismo de Estado" que apelaba a los lazos históricos de las naciones sudamericanas y que rememoraba la gesta independentista conseguida de manera compartida (López 2011).

A diferencia de otros intelectuales liberales que idealizaban y sentían una profunda admiración por el modelo federativo de los Estados Unidos, Vicuña Mackenna conoció de primera mano la política exterior y los afanes expansionistas del país del norte. No obstante haber esbozado estas críticas en años anteriores a la creación de la Sociedad de Unión Americana, fue sin duda esta experiencia como agente confidencial la que le imprimió un sello particular a su concepción sobre el americanismo.

Sin ánimo de extenderme en las acciones que emprendió, quisiera destacar dos hitos que permiten comprender su pensamiento sobre la soberanía continental y el grado de sistematicidad que adquirieron las premisas bolivarianas en el marco de su ideario liberal. Primero, el cuestionamiento a la Doctrina Monroe, y segundo, el llamado a la insurrección e independencia de Cuba.

Durante el gobierno de James Monroe (1817-1825) se fijó la posición internacional de Estados Unidos a través del principio conocido, hasta hoy, por su nombre y proclama de "América para los americanos". Anunciada el 2 de diciembre de 1823 ante el Congreso, el presidente declaraba que:

Los continentes americanos, por las condiciones de libertad e independencia que han asumido y mantenido, no deben ser considerados, de hoy en adelante, como entidades sometidas a una colonización futura por parte de cualquier potencia europea [...] debemos considerar cualquier esfuerzo que éstas hagan para extender su sistema a cualquier parte de este hemisferio como peligroso para nuestra paz y seguridad [...]

\footnotetext{
las tensiones entre las agendas propias de las repúblicas, los conflictos pendientes y el interés particular por salvaguardar las coyunturas nacionales particulares. Sobre el Congreso, ver Dargent (2007).

${ }^{12}$ Casi simultáneamente, estos tres países del Atlántico (Argentina, Brasil y Uruguay) combatieron con Paraguay en un conflicto bélico que se extendió desde 1865 hasta 1870 .

${ }^{13}$ Conviene recordar que en 1865 Estados Unidos había finalizado recientemente la Guerra de Secesión y empezado su etapa de reconstrucción tras el asesinato de Lincoln. La unión de los estados se había mantenido, pero tanto el Ejecutivo como el Congreso trataban de imponer sus puntos de vista sobre la consolidación de la unidad nacional. La política exterior había mejorado las relaciones con Francia e Inglaterra y los lazos se mantenían cordiales con España. Al respecto, ver Guerrero y Guerrero (1998).
} 
Por consiguiente, no nos es posible contemplar con indiferencia cualquier forma de intromisión (Bartlett 1954, cit. en Guerrero y Guerrero 1998: 103-104).

Tras ello se fijaba una posición internacional de progresivo abandono del aislacionismo que había caracterizado la política exterior estadounidense desde los tiempos de George Washington. De hecho, y poco antes del arribo de Vicuña Mackenna, el mandatario James Buchanan (1857-1861) planteó al Congreso la necesidad de que su país cumpliera una función policial en América Central y el Caribe, arguyendo la necesidad de proteger los intereses comerciales de los ciudadanos estadounidenses y de controlar las rutas comerciales frente al avance europeo. Aunque el Congreso no accedió a la petición, sí marcó un precedente sobre la afirmación del poder territorial entendido como consecuencia natural de la Doctrina Monroe y como una teoría del "Destino Manifiesto" que el país asumiría, en el futuro, dentro del concierto internacional (Freeman 2000: 76).

Considerándola una proclama en defensa de la soberanía de los Estados recientemente independizados, Vicuña Mackenna exigió la puesta en práctica de la doctrina ante el contexto de agresión en Sudamérica. Sin embargo, a poco andar, comprendió que el Estado norteamericano no accedería a tal petición pues buscaba mantener su neutralidad con tal de favorecer y fortalecer sus intereses económicos y territoriales (Donoso 1925; Guerrero 1986). Ante esta negativa, desarrolló una serie de actividades para dar a conocer las diferencias entre el "monrovismo" y el "bolivarismo", como mítines, conferencias, declamaciones y folletos (Vicuña Mackenna 1867).

Su visión se sustentaba en un marco más amplio de cuestionamientos a la política exterior estadounidense derivada de las expediciones filibusteras en Centroamérica y de su intervención en Texas. Estos sentimientos de desconfianza que, como dijimos, se profundizaron en la década de 1860, condujeron a algunos intelectuales -entre ellos, Vicuña Mackenna y Justo Areteaga Alemparte- a la convicción de que existían contradicciones insuperables en las vías de desarrollo de ambas Américas (Rinke 2014).

Bajo ese marco podemos leer su postura sobre la inutilidad de exigir la aplicación de los principios de dicha doctrina. Sin desconocer el republicanismo y los ideales democráticoliberales que hacían de Estados Unidos parte del horizonte cultural del "Nuevo Mundo", para el agente confidencial este postulado se había convertido en una "farsa de partido" que sólo se invocaba en época de elecciones o de agitación política y que, esgrimida hacia el exterior, servía únicamente para intimidar a los europeos y adquirir prestigio frente a las "naciones débiles de América”. Reinterpretando sus principios, sólo los países de América del Sur la habían llevado a cabo al fundar alianzas y tratados comunes y al defender con "sangre, fraternidad y gloria" los sacrificios independentistas alcanzados (Vicuña Mackenna [1856] 1872b: 376).

En una conferencia pronunciada en el Cooper Institute el 6 de enero de 1866, y reproducida al día siguiente en los diarios Herald y New York Times, el enviado del gobierno chileno expresaba:

En el concepto de los pueblos de Sudamérica, la doctrina Monroe no significa despojo, sino derecho; no significa invasión sino justicia [...] según nosotros la 
entendemos, es un principio vital absoluto, no un interés pasajero de política; no es una cuestión de geografía envuelta en esta cita popular -América para los americanos-; no es una cuestión de fronteras o territorios, por la cual este o aquel Estado puede engrandecerse a expensas de otro. Es, al contrario, la base del derecho mismo internacional de la América (Vicuña Mackenna 1867 vol.1: 279).

Esta referencia explica el pragmatismo y el cuestionamiento a la extrapolación idealista del liberalismo representado por Estados Unidos, además de su reivindicación sudamericana de la doctrina. En última instancia, para el político, esta parte del hemisferio no había escrito consignas en libros sino en el campo de batalla mismo. Por ello, y en tanto simbolizaba la "república eterna, la democracia eterna y la libertad eterna", la Doctrina Monroe debía cambiar de nombre y de patria, alojándose en las sociedades de unión americanas que se habían convocado como respuesta a los afanes de reconquista metropolitanos (Vicuña Mackenna [1856] 1872b: 377).

Sin embargo, esta visión del "americanismo radical" (López 2011) chocaba en buena medida con la realidad continental. Además de la guerra que enfrentaba a la Triple Alianza (Argentina, Brasil y Uruguay) contra Paraguay, la posición oficial del gobierno chileno en el Congreso de Lima, representada por el expresidente conservador Manuel Montt, evidenciaba las tensiones entre un discurso proclive a la unidad y las acciones concretas destinadas a resguardar el interés nacional ${ }^{14}$ (Dargent 2007: 448).

Bajo esa premisa, ¿cómo explicar el interés por la independencia centroamericana y del Caribe que el gobierno chileno le encomendó a Vicuña Mackenna como parte de su misión? ¿Guardaba relación con la idea de hacer grande a Hispanoamérica frente a Estados Unidos? O, ¿se comprendía que la expansión pasada y presente de las fronteras estadounidenses terminaría por alterar los equilibrios de poder en el continente? Sin aclarar este tipo de intenciones a largo plazo, Vicuña Mackenna explicitaba que su objetivo era establecer relaciones con las asociaciones de refugiados de Cuba y Puerto Rico con el fin, pragmático, de debilitar a Espańa. Entendiendo que ello se lograría con la autonomía antillana, fundó el periódico La Voz de la América. Órgano político de las Repúblicas Hispanoamericanas y de las Antillas Españolas, en cuyas páginas dio a conocer su postura sobre el estado colonial de Cuba, el rol que debían cumplir los partidos políticos en el proceso insurreccional, la conflictiva relación que preveía con Estados Unidos y la continuidad de la lucha caribeña con las independencias llevadas a cabo en el cono sur. ${ }^{15}$

\footnotetext{
${ }^{14}$ Para Germán de la Reza, las razones que explican el fracaso de los proyectos confederativos - desde 1826 en adelante- se debieron no sólo a la inestabilidad política y económica de la región, sino, ante todo, al rechazo legislativo de las propias clases dirigentes en el poder. En términos prácticos, la búsqueda de consolidación de los nuevos Estados en el concierto internacional contradecía las funciones supranacionales que les restaban soberanía en materia defensiva y comercial (2010: 90-91).

${ }^{15}$ Según Ricardo Donoso (1925), Vicuña Mackenna corregía personalmente las pruebas de imprenta y disponía la distribución de los dos mil impresos, mil de los cuales se enviaban a Cuba, doscientos a Chile, y el resto se entregaba a las legaciones hispanoamericanas asentadas en Washington.
} 
A mediados de 1860 la mayor parte de la elite económica cubana concentró sus esfuerzos en obtener de España las reformas necesarias que le aseguraran la libertad de comercio, la abolición gradual de la esclavitud y una participación creciente en el gobierno colonial. Ante la negativa de los peninsulares, en 1865 el movimiento partidario de la reforma cobró ímpetu en hacendados como Carlos Manuel de Céspedes, quien dirigió un alzamiento armado en octubre de 1868, iniciando el conflicto que posteriormente se conoció como la "Guerra de los Diez Años" (Aguilar 1992; Naranjo y García 1996).

Aunque desde 1870 se evidenció en la isla el crecimiento y madurez de una "formulación moderada del nacionalismo cubano en su vertiente autonomista" (García y Naranjo 2010: 118), lo cierto es que cuando Vicuña Mackenna escribió sus artículos existía una minoría de cubanos partidarios de la independencia. La mayoría aspiraba a una Cuba con estrechos lazos económicos con los Estados Unidos, viendo incluso con buenos ojos la anexión del territorio (Aguilar 1992: 215). Por ello, y crítico al actuar de los liberales en la isla, se hizo partícipe de las consignas levantadas por el Partido Revolucionario instando a los primeros a dar un paso al costado debido a su carácter reformista y sus afanes de negociación. Llamándolos a tomar las armas, en la editorial del primer número de $L a V o z$ de la América escribió:

¡Cubanos! Sed dignos de esa promesa y de ese pacto que os fue prometido hace cerca de medio siglo por Bolívar. Aprontaos con varonil esfuerzo para secundar la empresa, y cuando sintáis un día el estruendo del cañón en vuestras playas, no temáis que sea la vieja señal de los filibusteros, sino la salva de los hermanos que llegan a sellar en vuestras campanas la alianza de la América libre, republicana y unida con la misma sangre en que sus mayores iniciaron la empresa en Maipú y Carabobo (La Voz de la América 1866: 27).

Tal como en su temprano artículo de 1856, la unión continental y la identidad americana fundía sus raíces y se afirmaba solo en la América independizada de España. Por ello, instaba a los antillanos a no invocar la Doctrina Monroe, pues "Durante medio siglo, el águila del Norte contempla desde los sombríos farellones de las costas de Florida [...] aquella presa de su codicia y aguarda con sus alas desplegadas sólo la ocasión propicia para lanzarse sobre ella y anexarla" (1867: 191. Destacado en el original). Y en este diagnóstico, el político liberal no se equivocaba: el interés norteamericano sobre Cuba se había reactivado tras la Guerra Civil, abrigando el propósito de crear en el Caribe y en el Golfo de México una gran esfera de influencia que aseguraría el acceso al Mississippi y el control del paso interoceánico en Panamá (Freeman 2000).

Utilizando como ejemplo a Sudamérica, veía en la conciencia independentista cubana el único camino para entrar en las "leyes naturales" de la Historia y del progreso civilizatorio. Y su afán, declaraba, no era puramente discursivo. La independencia de la isla contribuiría al lógico perfeccionamiento humano, pero, además, y en concordancia con el ideario económico liberal, permitiría avances comerciales para "el mundo entero", pues su 
posición geográfica la convertía en el "más admirable depósito de todas las riquezas y de todas las transacciones entre los mares de Occidente y los mercados de Europa" ( $L a$ Voz de la América 1866: 2).

Sintiéndose continuador de la gesta mancomunada emprendida por el ejército libertador de los Andes, escribió a los gobiernos de Chile, Perú y Venezuela con el objeto de financiar una expedición militar que tuviese a Cuba como avanzada revolucionaria. Con ese fin, el 20 de abril de 1866, dirigió una carta confidencial al canciller chileno Álvaro Covarrubias en la que planteó dicho proyecto:

La idea que me permito sugerir a US. es la de una expedición chileno-peruana de dos mil hombres que, viniendo por el Istmo, desembarcase al sur de la Isla y la levantase. Este plan es mucho menos difícil de lo que parece a primera vista. El Callao, punto necesario y estratégico de partida de una empresa de este género, no está a mayor distancia náutica de los puertos del Sud de Cuba que de Valparaíso. Bastarían doce días o dos semanas para transportar dos mil hombres a cualquiera de esos puertos... uno o dos días podrían emplearse en el paso del Istmo (para el que estrictamente no se necesitan más de ocho horas) y de dos a tres días a cualquiera de los puertos de Cuba, desde Cienfuegos en el centro a Santiago de Cuba, en la extremidad oriental de la Isla (citado en Orrego 1951: 28-29).

Nunca obtuvo respuesta del canciller chileno. Por su parte, los líderes peruano y venezolano felicitaron su acción, pero se excusaron de entregarle apoyo por falta de recursos de sus Estados (Orrego 1951). Pese a ello, lo interesante de su iniciativa es que reactualizaba los ideales bolivarianos, situándolos en una experiencia concreta de unión que buscaba hacer frente tanto al poder europeo como al estadounidense.

Producto de estas acciones, y acusado de violar las leyes de neutralidad tras la compra de buques, fue enviado de regreso a Chile en junio de 1866. Por su iniciativa el embajador chileno en Estados Unidos, Astaburuaga, sostuvo un tiempo los contactos con la Sociedad Republicana de Cuba y Puerto Rico, además de financiar, hasta enero de 1867, el periódico La Voz de la América (López 2011: 178).

Aunque no está dentro los propósitos de este ensayo evaluar el impacto efectivo de sus consignas en los movimientos anticoloniales desarrollados en Cuba, Orrego afirma que su influjo se sintió en el período que precedió a la insurrección separatista llevada a cabo por Céspedes en 1868 (1951: 15). De hecho, cuando Vicuña Mackenna conoció la noticia sobre el alzamiento, manifestó abiertamente su apoyo desde su posición de Senador en el Parlamento. En ese sentido, su comprensión del americanismo, proyectado sobre el territorio de las Antillas, evidenciaba un compromiso que trascendía al gobierno, interesado en esa coyuntura en alcanzar la paz con Espańa y reestablecer las relaciones internacionales con Francia e Inglaterra. Para la elite gobernante, el éxito de ambas tareas se lograría alineando de forma transversal a sus segmentos disidentes, y para ello, había que desactivar el ímpetu americanista nacido a inicios de 1860 . 
Hacia fines de esta década, y sin un enemigo en el horizonte contra el cual pelear, gran parte de la clase dirigente optó por un pragmatismo destinado a retomar los asuntos internos. La reconstrucción tras el bombardeo en Valparaíso, y la recuperación del poderío económico en el Pacífico, marcaron desde entonces la agenda y las preocupaciones oficiales, finalizando así el incipiente apoyo al independentismo antillano y a casi una década de "americanismo de Estado" (López 2011: 188).

Respecto al pensamiento y acción de Vicuña Mackenna, resulta de interés destacar que en estos años no antepuso una forma idealizada y romántica del ideario liberal americanista, sino que lo situó concretamente en función del escenario, la experiencia y las condiciones de los países y sus gobernantes. En ese marco, el espacio discursivo y político que emprendió en y desde Estados Unidos, le permitió sistematizar y madurar una concepción bolivariana que simbolizaba la unión de las repúblicas hispanoamericanas frente a las naciones europeas y a las doctrinas monrovistas nacidas en suelo angloamericano.

\section{RefLeXIONES FinALES}

Los procesos independentistas generaron en la elite un sentido de pertenencia derivado de una historia común de lucha anticolonial. Hacia 1860, sobre este sustrato inicial, emergió un americanismo que se nutrió de nuevas experiencias asociadas a la soberanía de los Estados construidos, al respeto por el constitucionalismo y a la confianza en el republicanismo. Las reflexiones e ideas de América que expresaron los liberales chilenos en el marco de la Sociedad de Unión Americana ilustran la defensa de estos valores alcanzados décadas después de luchas internas en estas naciones.

Además de las disputas por la laicización de la sociedad y de las divergencias respecto a la concentración de poder en el Ejecutivo o en el Parlamento, resulta de interés comprender la concepción de americanismo y la visión sobre Estados Unidos a la hora de indagar en el espectro ideológico de los liberales de mediados del siglo XIX. Las generalizaciones han tendido a adjudicarles un entusiasmo por el modelo norteamericano, mientras que a los conservadores se les ha atribuido un rescate de los valores monárquicos españoles. En ese marco, la particular perspectiva de Vicuña Mackenna evidencia que las diferencias al respecto no fueron tan marcadas ni claras y que hubo variantes en los modelos de referencia de construcción republicana.

Empíricamente se puede identificar el americanismo en los congresos convocados a raíz de las intervenciones europeas y de la política exterior estadounidense. Aunque ello no quiere decir que este pensamiento haya nacido ni sea exclusivo de estas instancias institucionales, las medidas aprobadas a mediados de 1860 en el Congreso Americano de Lima consolidaron y legitimaron el ideario liberal en detrimento de los conservadores, ilustrando su afán por desarrollar estructuras que le permitieran al país insertarse en el concierto capitalista internacional.

Si bien a la distancia el movimiento americanista de la década de 1860 puede interpretarse como un recurso retórico y político coyuntural, lo cierto es que para entonces 
las propias experiencias personales de sus participantes -algunos de ellos exiliados por el gobierno conservador de Manuel Montt- incidieron a la hora de plantear un horizonte de libertad y democratización continental. Claramente el lugar de enunciación de este llamado fue desde una zona de privilegio. No podemos dejar de mencionar que en la década de 1880 Vicuña Mackenna fue el principal defensor de la guerra que Chile emprendió contra Perú y Bolivia y que apoyó fervientemente la ocupación de la Araucanía y la expansión del Estado en territorio mapuche. Sin embargo, no es menos cierto que en medio de las intervenciones europeas, el americanismo que propuso asentó las bases críticas del expansionismo estadounidense.

Hacia fines del siglo XIX, el término "yanqui" unió un discurso económico y cultural que expresaba el "otro americano extranjero" y un símbolo politizado en luchas de poder y reconocimiento latinoamericano (Rinke 2014: 152). Aunque se popularizó en el siglo XX, Vicuña Mackenna utilizó tempranamente el vocablo - "yankee" en su caso- para denotar un cierto espíritu configurador del ser estadounidense. En ocasiones, para hablar de una raza particular - una "raza indefinida [...] aglomeración de todas las razas humanas" (1867: 161)-; en otras, para ilustrar formas de comportamiento -la suspicacia, el afán por el comercio y la competencia (1867: 296)-; y, en términos más amplios, para aludir a una conducción de la política exterior que conjugaba una falsa neutralidad con claros afanes de intromisión y anexión. En ese sentido específico, su pensamiento precedió al "antiyanquismo" que desde 1920 se convirtió en parte del fervor emotivo de los movimientos reformistas de corte nacionalista y en un aspecto central de la retórica política en América Latina.

Queda claro que las diferentes visiones sobre el americanismo sesentero del siglo XIX en ningún caso alteraron el orden oligárquico existente. Así como en estos años existió este y otros aspectos de discordia, hubo consensos sustanciales que permitieron que la elite mantuviera su poder, en tanto clase dirigente, hasta bien entrado el siglo XX. Entre ellos, el rechazo y el enfrentamiento político y militar ante los avances del movimiento obrero, o la creencia casi irrestricta en el funcionamiento del libre mercado. Pese a estos aspectos aglutinantes, este ensayo intentó evidenciar que una perspectiva homogénea no permite apreciar los matices que, en un plazo más largo, se materializaron en las fracturas oligárquicas de 1891 y 1920.

Bien se puede argumentar que la pregunta sobre la inclusión de Estados Unidos o el cómo definir los parámetros de su participación siguen siendo temas de controvertida actualidad. Avanzada la segunda mitad del siglo XIX fue este país el que tomó la iniciativa de integración continental, convocando en 1889 a la primera Conferencia Panamericana que conduciría más tarde a la creación de la Organización de Estados Americanos (1948). Pese a estos afanes, las críticas al expansionismo norteamericano -rotulado en el siglo XX como imperialismo- no cesaron y, por el contrario, se agudizaron tras la revolución cubana de 1959. En ese marco, quedan todavía una serie de preguntas por responder: ¿Es posible conectar la visión de Vicuña Mackenna con los postulados antimperialistas? ¿qué impacto tienen hoy los principios del monrovismo y del bolivarismo en Sudamérica? ¿qué individuos y colectivos encarnarían en el presente un discurso americanista? Estas últimas 
son interrogantes y preocupaciones que permanecen en el horizonte y que llaman, a inicios del siglo XXI, a fortalecer el debate sobre los términos y alcances de la integración social y continental de estas naciones.

\section{OBRAS CITADAS}

Aguilar, Luis. 1992. "Cuba, c. 1860-1934”. En Leslie Bethell, Ed., Historia de América Latina Vol. 9: México, América Central y el Caribe, c. 1870-1930. Barcelona: Crítica. 73-105.

Anderle, Adam. 1988. "El positivismo y la modernización de la identidad nacional en América Latina". Anuario de Estudios Americanos 45: 419-484.

Brintrup, Lilianet. 1993. "El libro móvil: viaje y escritura en algunos viajeros chilenos del siglo XIX”. Revista Chilena de Literatura 42: 57-64.

Castillo, Vasco. 2003. "El Estado republicano en el debate "República-democracia". En Alejandra Castillo, Eva Muzzopappa, Alicia Salomone, Bernarda Urrejola y Claudia Zapata, eds., Nación, Estado y Cultura en América Latina. Santiago: Ediciones de la Facultad de Filosofía y Humanidades, Universidad de Chile. 123-160.

Cavieres, Eduardo. 2001. "Anverso y reverso del liberalismo en Chile, 1840-1930". Historia 34: 39-66.

Collier, Simon. 2005. La construcción de una república, 1830-1865. Politica e ideas. Santiago: Ediciones Universidad Católica.

Dargent, Eduardo. 2007. "Repúblicas fraternas y rivales. Discurso republicano en el Congreso Americano de 1864”. En Carmen Mc Evoy y Ana María Stuven, eds., La república peregrina. Hombres de armas y letras en América del Sur, 1800-1884. Lima: Instituto de Estudios Peruanos. 443-468.

De la Reza, Germán. 2010. “La asamblea hispanoamericana de 1864-1865, último eslabón de la anfictionía”. Estudios de historia moderna y contemporánea de México 39: 71-91.

Donoso, Ricardo. 1925. Don Benjamin Vicuña Mackenna: su vida, sus escritos y su tiempo. Santiago: Universitaria.

Freeman, Robert. 2000. "América Latina, los Estados Unidos y las potencias europeas, 1830-1930". En Leslie Bethell, ed., Historia de América Latina Vol. 7: Economía y sociedad. Barcelona: Crítica. 73-105.

García, Luis \& Consuelo Naranjo. 2010. "Intelectualidad criolla y nación en Cuba, 18781898". Studia Histórica. Historia Contemporánea 15: 115-134.

Gazmuri, Cristián. 2006. La historiografía chilena (1842-1970). Santiago: Aguilar Chilena Ediciones.

Guerrero, Cristián. 1986. "La misión de Vicuña Mackenna a los Estados Unidos (18651866)”. Revista Atenea 452-454: 239-275.

Guerrero, Cristián \& Cristián Guerrero Lira. 1998. Breve historia de los Estados Unidos de América. Santiago: Universitaria. 
Jocelyn-Holt, Alfredo. 1998. "El liberalismo moderado chileno. Siglo XIX". Estudios Públi$\cos$ 69: 439-485.

Koselleck, Reinhart. 1993. Futuro pasado: para una semántica de los tiempos históricos. Madrid: Paidós.

Lacoste, Pablo. 1997. "Americanismo y guerra a través de El Mercurio de Valparaíso (18661868)". Anuario de Estudios Americanos 54: 567-591.

López, Ricardo. 2013. Prólogo a La Patria común. Pensamiento americanista en el siglo XIX. Álvaro Covarrubias, Benjamín Vicuña Mackenna, Domingo Santa María y José Victorino Lastarria. Selección y prólogo de Ricardo López. Santiago: Lom Ediciones. . 2011. El americanismo en Chile ante la expansión política y militar europea sobre Hispanoamérica (1861-1871). Tesis para optar al grado de Doctor en Estudios Latinoamericanos, Universidad de Chile.

Naranjo, Consuelo y Armando García. 1996. Racismo e inmigración en Cuba en el siglo XIX. Madrid: Ediciones Doce Calles.

Orrego, Eugenio. 1932. Vicuña Mackenna: vida y trabajos. Santiago: Universidad de Chile. . 1939. Iconografía de Vicuña Mackenna. Santiago: Universidad de Chile. . 1951. Vicuña Mackenna y la independencia de Cuba. La Habana: Imprenta el Siglo.

Pratt, Mary Louise. 1997. Ojos imperiales. Literatura de viajes y transculturación. Buenos Aires: Ediciones de la Universidad de Quilmes.

Quijada, Mónica. 1998. "Sobre el origen y la difusión del nombre América latina (o una variación heterodoxa en torno al tema de la construcción social de la verdad)". Revista de Indias 214: 595-615.

Renique, José Luis. 2007. “Benjamín Vicuña Mackenna: exilio, historia y nación”. En Carmen McEvoy y Ana María Stuven, eds., La república peregrina: hombres de armas y letras en América del Sur, 1800-1884. Lima: Instituto de Estudios Peruanos. 487-529.

Rinke, Stefan. 2014. Encuentros con el yanqui: norteamericanización y cambio sociocultural en Chile, 1898-1990. Santiago: Centro de Investigaciones Barros Arana/Pontificia Universidad Católica de Valparaíso.

Rojo, Grínor. 2001. "Nota sobre los nombres de América”. Atenea 483: 63-76.

Romero, José Luis. 1976. Latinoamérica: las ciudades y las ideas. Buenos Aires: Siglo XXI.

Sagredo, Rafael. 1996. "Elites chilenas en el siglo XIX. Historiografía". Cuadernos de Historia 16: 103-132.

Sanhueza, Carlos y Javier Pinedo. 2010. La patria interrumpida. Latinoamericanos en el exilio. Santiago: Lom Ediciones.

Stuven, Ana María. 2000. La seducción de un orden. Las elites y la construcción de Chile en las polémicas culturales y politicas del siglo XIX. Santiago: Ediciones Universidad Católica de Chile.

. 2005. "Republicanismo y liberalismo en la primera mitad del siglo XIX: ¿hubo proyecto liberal en Chile?”. En Manuel Loyola y Sergio Grez, comps., Los proyectos nacionales en el pensamiento politico y social chileno del siglo XIX, Santiago: Ediciones Universidad Católica Silva Henríquez. 61-73. 
. 2007. Historia de las ideas y de la cultura en Chile. Tomo I: Sociedad y cultura liberal en el siglo XIX. José Victorino Lastarria. Santiago: Universitaria.

Subercaseaux, Bernardo. 1980. "Visión de Estados Unidos y América en la elite liberal (1860-1870)". Revista Araucaria 11: 21-36.

Vicuña, Manuel. 2009. Un juez en los infiernos. Benjamín Vicuña Mackenna. Santiago: Ediciones Universidad Diego Portales.

FuENTES CONSULTADAS

La Voz de la América. Órgano político de las Repúblicas Hispanoamericanas y de las Antillas Españolas. Nueva York, 1866.

Sociedad de Unión Americana. 1867a. Colección de ensayos y documentos relativos a la Unión y Confederación de los pueblos sud-americanos, Tomo II. Santiago: Imprenta del Ferrocarril.

Sociedad de Unión Americana. 1867b. Bases de Unión Americana discutidas y aprobadas por la Sociedad de Unión Americana de Santiago. Santiago: Imprenta de la Libertad.

Vicuña Mackenna, Benjamín. 1867. Diez meses de misión a los Estados Unidos de Norte América como agente confidencial. Santiago: Imprenta de la Libertad.

Vicuña Mackenna, Benjamín. [1856] 1872a. "La conquista de la América española por los americanos del norte". Miscelánea. Colección de artículos, discursos, biografías, impresiones de viaje, ensayos, estudios sociales, económicos, etc., Tomo II. Santiago: Imprenta de la librería del Mercurio.

Vicuña Mackenna, Benjamín. [1856] 1872b. "La doctrina Monroe y la unión americana”. Miscelánea. Colección de artículos, discursos, biografías, impresiones de viaje, ensayos, estudios sociales, económicos, etc., Tomo I. Santiago: Imprenta de la librería del Mercurio. 